\title{
Novel DNA-based test for the identification of benthic diatoms of European freshwater waterbodies (WAT-DIMON)
}

\author{
Panayiota Pissaridou $\ddagger$, Athina Papatheodoulou§, Gregoris Notarides $¥$, Juan Antonio Villaescusal,

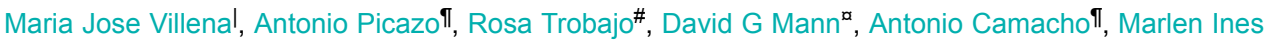 \\ Vasquez Hadjilyra $¥$ \\ ‡ Cyprus University of Technology, Limassol, Cyprus \\ $\S$ IACO Ltd, Nicosia, Cyprus \\ | Laboratorios Tecnológicos de Levante (LTL), Valencia, Spain \\ I University of Valencia, Valencia, Spain \\ \# IRTA, Sant Carles de la Rapita, Spain \\ a Royal Botanic Garden Edinburgh, London, United Kingdom
}

Corresponding author: Panayiota Pissaridou (panayiota.pissaridou@cut.ac.cy),

Marlen Ines Vasquez Hadjilyra (marlen.vasquez@cut.ac.cy)

Received: 27 Feb 2021 | Published: 04 Mar 2021

Citation: Pissaridou P, Papatheodoulou A, Notarides G, Villaescusa JA, Villena MJ, Picazo A, Trobajo R, Mann DG, Camacho A, Vasquez Hadjilyra MI (2021) Novel DNA-based test for the identification of benthic diatoms of European freshwater waterbodies (WAT-DIMON). ARPHA Conference Abstracts 4: e65203.

https://doi.org/10.3897/aca.4.e65203

\begin{abstract}
Diatoms are unicellular eukaryotic organisms, which have been exploited over the years for effective freshwater bioassessment. Therefore, they are excellent bioindicators, routinely used in national environmental monitoring programs all over Europe within the Water Framework Directive (WFD) 2000/60 /EC (Foster et al., 2000) and CEN standards (CEN, 2018).

Over the years, new technologies have been introduced to this field to maximise and improve the time and cost required for freshwater bioassessment. The application of DNA metabarcoding for the characterisation of benthic diatom communities for WFD was recently introduced (Vasselon et al. 2017, Kelly et al. 2018). Through this technique, the identification of the species present in one environmental sample, is established using
\end{abstract}


genetic variability and is characterised by a short DNA fragment called a barcode (Vasselon et al., 2019).

The Wat-Dimon Eurostars project aim at creating a novel genomic test for the identification of European benthic diatoms. This new DNA-based test could be routinely implemented in national environmental monitoring programs all over Europe within the Water Framework Directive (WFD) 2000/60 /EC and CEN standards. In the near future, metabarcoding can complement and/or replace the traditional ecological assessments based on the morphotaxonomy methodology approach needing taxonomic expertise and been subjected to scientific bias. Additionally, the project aims at developing a complementary bioinformatics tool for the biotechnological interpretation of the results. Such product will allow the prompt response to the environmental needs, the early assessment of environmental quality and early treatment response. The study will be developed and validated along a longitudinal gradient in the south part of Europe (Portugal, Spain, Cyprus), including four different biogeographical regions (Macaronesia, Atlantic, Alpine and Mediterranean). The method will cover all steps, from sampling and DNA extraction of diatom assemblages and amplification of DNA barcodes using universal primers for diatoms. The amplified products will be sequenced using Illumina MiSeq. Then, existing bioinformatic pipelines will be adjusted to quality-filter the high number of sequences from the samples and identify them by comparison with reference databases (Diat.Barcode, BOLD, GenBank). Enhancing these databases with diatom species prevalent in the different biogeographical regions assayed will be essential as existing databases are biased to more northerly regions and do not take into consideration harsh, extreme climatic conditions which are prominent in the Mediterranean and Macaronesia regions (Fig. 1). The project focuses on the rbcL gene and will used $18 \mathrm{~S}$ gene only as an alternative or complementary tool if any problematic taxa appear.

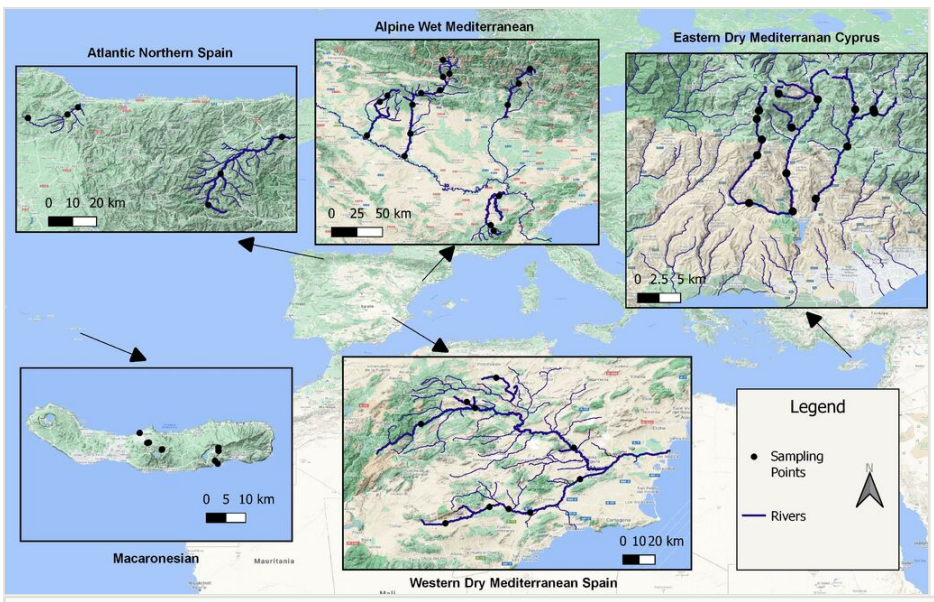

Figure 1. doi

Compiled map for the representation of European specific monitoring network for the WatDimon project 
CEN, 2018. CEN/TR 17245: Water quality - Technical report for the routine sampling of benthic diatoms from rivers and lakes adapted for metabarcoding analyses. CEN/TC 230/ WG 23 - Aquat. Macrophytes Algae 1-8. https://doi.org/CEN/TR 17245:2018

Foster, D., Wood, A., Griffiths, M., 2000. THE WATER FRAMEWORK DIRECTIVE (2000/60/EC) - AN INTRODUCTION Dave Foster - Policy Advisor (Europe), Aram Wood EP Scientist (Water), Dr Martin Griffiths - Head of Water Quality, Environment Agency, Head Office, Rio House, Waterside Drive, Aztec West, Almon 7-9.

Kelly et al. (2018). A DNA based diatom metabarcoding approach for Water Framework Directive classification of rivers. Environment Agency.

Vasselon et al. (2017). Assessing ecological status with diatoms DNA metabarcoding: Scaling-up on a WFD monitoring network (Mayotte island, France). Ecological Indicators. 82:1-12

Vasselon, V., Rimet, F., Domaizon, I., Monnier, O., Reyjol, Y., Bouchez, A., 2019. Assessing pollution of aquatic environments with diatoms' DNA metabarcoding: Experience and developments from France Water Framework Directive networks. Metabarcoding and Metagenomics 3, 101-115. https://doi.org/10.3897/mbmg.3.39646

\section{Presenting author}

Athina Papatheodoulou

\section{Presented at}

1st DNAQUA International Conference (March 9-11, 2021)

\section{Funding program}

Eureka Eurostars, European Union Regional Development Fund, Structural Funds of European Union in Cyprus, Republic of Cyprus, Research And Innovation Foundation, Restart 2016-2020 